\section{Эффективность сортовых тополей в степной зоне}

\author{
B. А. Царев ${ }^{1}$ \\ Воронежская лесотехническая академия
}

\begin{abstract}
АННОТАЦИЯ
Изложены результаты сортоиспытания более 40 различных форм, клонов и сортов тополей в степных условиях Волгоградской области. Проанализированы укореняемость, рост и сохранность тополей, устойчивость их к биотическим и абиотическим факторам среды, продуктивность в сравнении с контролем местным черным тополем (осокорем). По результатам научных исследований разработан ассортимент, состоящий из клонов следующих евро-американских сортов: Бахельери, Брабантика, Вернирубенс, Каролинский, Мариландика, Регенерата, Робуста и Серотина.
\end{abstract}

Ключевые слова: тополь, гетерозис, отбор, сортоиспытание, интродукии, ассортимент, укореняемость.

\section{SUMMARY}

The results of more than 40 different poplar cultivars and clones tested at Volgograd region are considered. The rooting, growth, viability and resistance to abiotic and biotic environment factors are studied. As a control there was used the local clones of Populus nigra L. or average meaning of testing set of clones. There are found some best cultivars for that conditions. There are Bacheliery, Brabantica, Vernirubens, Caroline, Marilandica, Regenerate, Robuste and Serotine.

Keywords: poplar, heterosys, selection, testing of cultivars, introduction, assortment, rooting.

\section{ВВЕДЕНИЕ}

Волгоградская область относится к остро лесодефицитным регионам. Ее лесистость равна 3,9\%. Собственные леса обеспечивают потребность области в древесине лишь на $17 \%$ и не способны в полной мере проявить защитное воздействие против ветровой и водной эрозии, а также не позволяют решать озеленительно-рекреационные задачи. Поэтому создание здесь новых лесных насаждений из быстрорастущих пород позволит в какой-то степени снизить существующий дефицит полезностей леса.

Вопросами селекции древесных пород в данном регионе начали заниматься в пятидесятых годах прошлого столетия (ВНИАЛМИ). Широкую известность получил гибрид А. В. Альбенского тополь Пирамидально-осокоревый Камышинский с адаптивным и соматическим гетерозисом, выведенный при скрещи-

\footnotetext{
${ }^{1}$ Автор - ассистент кафедры экономики лесного хозяйства

(C) В. А. Царев, 2003
}

вании тополя черного пирамидального с осокорем. Впоследствии в данном регионе научные исследования были продолжены по интродукции тополей (Камышинская лесная опытная станция).

Исследования автора проводились на территории Подтелковского, Даниловского и Руднянского лесхозов Волгоградской области. Они включали изучение особенностей вегетативного размножения различных форм, клонов, гибридов и сортов тополей в зависимости от экологических и генотипических особенностей; оценку энергии роста и сохранности растений в опытно-производственных культурах; определение зимостойкости и степени повреждения болезнями и вредителями изучаемых тополей, отбор наиболее выдающихся культиваров и разработку ассортимента тополей для условий Волгоградской области.

\section{ОБЪЕКТЫ И МЕТОДЫ ИССЛЕДОВАНИЙ}

Объектами исследований являются 43 клона тополей, принадлежащих к подроду (Eupopulus Dode), в том числе 29 клонов из секции черных (Aigeiros Dubi), 8 клонов бальзамических (Tacamahaca Spach) и 6 межсекционных гибридов настоящих тополей. Более половины из них (24 клона) представлены спонтанными гибридами евро-американских тополей, интродуцированными в Россию из Западной Европы. В испытания также включены клоны из США и разных регионов России. Исследования проводились в укоренительных отделениях, на маточных плантациях и в опытных культурах, специально заложенных в регионе. Всего изучено 14 объектов на площади 12 га.

Кроме того, при содействии администрации НижнеВолжской селекционной станции ВНИАЛМИ дополнительно проведены исследования на Камышинском сортоучастке, заложенном в 1986 г. на площади 2 га с густым размещением 1,5 × 1,0 м [2].

Закладка основной экспериментальной базы проведена под методическим руководством Р. П. Царёвой. Опыты создавались в соответствии с Методикой государственного сортоиспытания лесных пород (Общая часть) и Методикой сортоиспытания тополей, разработанных в Центральном НИИ лесной генетики и селекции. При этом размещение в укоренительных отделениях было 1,5 х 0,1 м и 3,0 х 0,1 м; на маточных плантациях - 3,0 х 0,5 м; в опытных культурах 4 × 2 м и 4 × 4 м.

Проведен корреляционный и регрессионный анализ приживаемости тополей в зависимости от сроков и густоты посадки и дисперсионный анализ влияния генотипа на рост тополей в культурах. Для обобщения результатов роста тополей в различных почвенно-экологических условиях проведено ранжирование по ряду изучаемых признаков: укореняемость стеблевых черенков, выход посадочного материала с единицы площади, приживаемость саженцев, сохранность в культурах, рост в высоту и по диаметру.

Зимостойкость тополей определялась по 6-балльной шкале С. А. Ростовцева (1961). Степень поражения 
фитопатогенами определялась в соответствии с Методическими указаниями Т. М. Хохряковой и И. И. Минкевича (1969); степень повреждения листогрызущими и вторичными энтомовредителями - по С. А. Ростовцеву (1961) [5].

Почвенный покров опытных участков представлен зональными черноземными суглинистыми и каштановыми супесчаными разностями, а также интразональными пойменными слоисто-зернистыми супесчаными и суглинистыми разностями с $\mathrm{pH}$ около 6 . Содержание гумуса в пахотном горизонте $2-3 \%$, в подпахотном - 0,5-1,8\%. В почвах почти отсутствуют легкорастворимые соли (сухой остаток $=0,1 \%$ ).

В качестве контроля приняты показатели энергии роста и продуктивности местного черного тополя (осокоря), а в некоторых случаях - средняя совокупности изучаемых признаков.

\section{РЕЗУЛЬТАТЫ И ОБСУЖДЕНИЕ}

При изучении размножения и репродуктивной способности различных форм тополя в условиях Волгоградской области установлено, что наиболее оптимальной густотой посадки стеблевых черенков для выращивания стандартного посадочного материала в укоренительных отделениях является густота 250 тыс. шт. на 1 га. Примерное размещение 20 х 20 см при площади питания каждого растения $0,04 \mathrm{~m}^{2}$. Для выращивания крупномерного посадочного материала густота посадки может быть снижена до 110-170 тыс. шт. на 1 га с размещением 30 х 30 и 40 х 35 см и площадью питания 0,09-0,15 м² [8].

Лучшими по укореняемости стеблевых черенков и росту 1-летних саженцев были клоны тополей волосистоплодного, Робусты-236, Каролинского-162, Брабантики-175 и 176, Бахельери, Сакрау-59, Ивантеевского, э.с.-38 и др.

Наибольший выход стеблевых черенков с маточных плантаций наблюдался в основном у представителей секции черных тополей и, как правило, у евроамериканских сортов. В 4-летнем возрасте они продуцировали 300-350 тыс. шт./га стеблевых черенков на супесчаных почвах в Руднянском лесхозе, 320600 тыс. шт./га - в пойменных условиях Даниловского лесхоза и 550-900 тыс. шт./га - на черноземных почвах при орошении в Подтелковском лесхозе.

Представители бальзамических тополей и большинство межсекционных гибридов показывали высокую репродуктивную способность и хороший рост лишь в первые 2-3 года. На 4-й год эксплуатации маточных плантаций они полностью погибли в Подтелковском лесхозе и резко снизили выход стеблевых черенков в других лесхозах. Наибольший интерес из них представляет лишь только гибрид э.с.-38.

Изучение роста и сохранности тополей в культурах проводилось в зависимости от сроков и густоты посадки, рельефа местности, от затопляемости пойменных участков и от генотипических особенностей то- полей. Полученные результаты показывают, что в условиях засушливого климата области сроки посадки оказывают существенное влияние на приживаемость тополей. Задержка посадки саженцев после готовности почвы (при накоплении после зимы суммы положительных температур, равной $50-70^{\circ} \mathrm{C}$ ) только на 5 дней влечет за собой снижение приживаемости на 9\%, на 14 дней - на 21-55\%. Это говорит о том, что посадку насаждений в регионе необходимо осуществлять в ранние и сжатые сроки.

Почти не было выявлено различий в приживаемости саженцев в зависимости от способов посадки (под посадочную машину или в свеженарезанные борозды) и густоты посадки (4 х 2 м и 4 х 4 м). Разница составляла $2-5 \%$. Густота посадки оказывала влияние на последующий рост культур. Анализ динамики роста тополей при разной густоте посадки показал, что различия в энергии роста наблюдаются с 3-летнего возраста, а в 5-летнем возрасте она была уже достоверна и составляла в среднем 20-23\%. На временно затопляемых пойменных участках энергия роста одних и тех же культиваров в среднем была выше на 18\%. В 5-летнем возрасте их высота составляла $4,5 \mathrm{~m}$.

Анализ роста тополей в мелиоративном фонде показал, что энергия их роста зависела от крутизны склона. Так, средняя высота всех испытываемых тополей, произрастающих в более ровной верхней части склона (гумуса $3,1 \%$ ), в 5-летнем возрасте была 5,7 м, диаметр - 6,7 см; на склоне балки в 3-10 градусов (гумуса $1,8-2,8 \%$ ) - 4,5 м и 5,3 см соответственно; на дне балки с намытым гумусовым слоем (гумуса 4,2\%) - 5,8 м и 7,1 см. Результаты 2-факторного дисперсионного анализа роста тополей в мелиоративном фонде показали, что сила влияния фактора «среда» на рост тополей составляла $12-14 \%$. В большей степени на рост испытываемых тополей оказывал влияние генотип $-25-27 \%$.

В таблицах 1-3 приведены показатели роста клонов тополей, произрастающих в культурах на трех основных участках, превышающие контроль.

Таблица 1

Показатели роста лучших сортов тополей по высоте в культурах Подтелковского лесхоза (возраст 5 лет)

\begin{tabular}{|l|c|c|c|c|}
\hline \multicolumn{1}{|c|}{$\begin{array}{c}\text { Наименование } \\
\text { тополя }\end{array}$} & $\begin{array}{c}\text { Инвен- } \\
\text { тарный } \\
\text { номер }\end{array}$ & $\begin{array}{c}N, \\
\text { экз. }\end{array}$ & $M$, м & $\pm m$ \\
\hline Бахельери & 157 & 33 & 5,0 & $0,18^{*}$ \\
Брабантика-175 & 55 & 54 & 4,0 & $0,14^{*}$ \\
Брабантика-176 & 56 & 8 & 4,5 & $0,22^{*}$ \\
Вернирубенс & 54 & 58 & 4,3 & $0,11^{*}$ \\
Каролинский-162 & 162 & 18 & 3,9 & 0,13 \\
Мариландика-239 & 190 & 71 & 4,1 & $0,11^{*}$ \\
Регенерата & 90 & 52 & 4,3 & $0,11^{*}$ \\
Робуста-195 & 33 & 64 & 4,1 & $0,11^{*}$ \\
Серотина-22 & 31 & 23 & 4,0 & 0,34 \\
Черный местный & - & 30 & 3,6 & 0,14 \\
\hline
\end{tabular}


Примечание: здесь и далее знаком (*) отмечены сорта тополя, достоверно превышающие контроль на 5-процентном уровне значимости.

В культурах Подтелковского лесхоза лучше контроля росли 10 клонов евро-американских тополей. Их средняя высота в 5-летнем возрасте варьировала от 4 до 5 м, в то время как контроль составлял 3,6 м.

Таблица 2

Показатели роста лучших сортов тополей по высоте в культурах Руднянского лесхоза (возраст 5 лет)

\begin{tabular}{|l|c|c|c|c|}
\hline \multicolumn{1}{|c|}{$\begin{array}{c}\text { Наименование } \\
\text { тополя }\end{array}$} & $\begin{array}{c}\text { Инвен- } \\
\text { тарный } \\
\text { номер }\end{array}$ & $\begin{array}{c}N, \\
\text { экз. }\end{array}$ & $M$, м & $\pm m$ \\
\hline Брабантика-175 & 158 & 113 & 4,7 & $0,09^{*}$ \\
Евро-американский & 160 & 108 & 4,7 & $0,10^{*}$ \\
Регенерата & 65 & 117 & 4,5 & $0,12^{*}$ \\
Робуста-195 & 33 & 75 & 5,4 & $0,14^{*}$ \\
Робуста-236 & $80 \mathrm{~A}$ & 237 & 5,8 & $0,09^{*}$ \\
Серотина & 31 & 167 & 4,6 & $0,07^{*}$ \\
Черный местный & - & 215 & 3,7 & 0,08 \\
\hline
\end{tabular}

Средняя высота лучших клонов в Руднянском лесхозе варьировала от 4,5 м до 5,8 м. Контроль здесь по высоте был близким к таковому в первом случае и составлял 3,7 м.

Таблица 3

Показатели высоты лучших сортов тополей на Камышинском сортоучастке (возраст 7 лет)

\begin{tabular}{|l|c|c|c|c|}
\hline \multicolumn{1}{|c|}{$\begin{array}{c}\text { Наименование } \\
\text { тополя }\end{array}$} & $\begin{array}{c}\text { Инвен- } \\
\text { тарный } \\
\text { номер }\end{array}$ & $\begin{array}{c}N, \\
\text { экз. }\end{array}$ & $M, \mathrm{M}$ & $\pm m$ \\
\hline Бахельери & 30 & 71 & 6,0 & 0,15 \\
Брабантика-175 & 55 & 35 & 7,0 & $0,20^{*}$ \\
Брабантика-176 & 56 & 39 & 6,0 & 0,21 \\
Вернирубенс & 54 & 35 & 6,6 & $0,20^{*}$ \\
Вернирубенс & 159 & 42 & 6,8 & $0,21^{*}$ \\
Регенерата & 79 & 17 & 6,1 & 0,21 \\
Робуста-236 & 156 & 42 & 6,2 & 0,16 \\
Среднее из 14 & - & 394 & 5,7 & 0,08 \\
клонов & & & & \\
\hline
\end{tabular}

Средняя высота тополей на Камышинском сортоучастке в 7-летнем возрасте варьировала от 6 до 7 м; в контроле она была 5,7 м.

Анализ зимостойкости тополей в условиях резко континентального климата Волгоградской области показал, что наиболее зимостойкими были представители бальзамических тополей и межсекционных гибридов. Однако эти тополя в данном регионе характеризуются пониженной энергией роста и низкой засухоустойчивостью, а в некоторых местах они даже полностью погибли. Поэтому они не представляют интереса для данной зоны.

Более продуктивными здесь были черные тополя и в особенности евро-американские гибриды, поэтому они представляют гораздо больший интерес для практического выращивания лесных искусственных насаждений. Повреждения их морозами в изучаемый период были незначительными и в основном только на молодых 1-летних побегах в укоренительных отделениях и на маточных плантациях (1 балл). Более сильные повреждения морозами (2,5 балла) были отмечены лишь у гибридов итальянской селекции (тополь I-488b).

Больше всех фитопатогенами и энтомовредителями поражались бальзамические тополя и межсекционные гибриды, у которых один или оба родителя были из секции бальзамических тополей. Относительно устойчивыми одновременно к морозам, болезням и вредителям были некоторые клоны евроамериканских тополей.

При ранговом методе оценки роста и устойчивости испытываемых тополей отобраны наиболее подходящие для данных условий культивары. В ассортимент вошли 15 лучших клонов тополей, среди них: два клона тополя Бахельери (инв. № 30 и 157), два клона Брабантики-175 (инв. № 55 и 158), Брабантика-176, два клона Вернирубенса (инв. № 54 и 159), евроамериканский № 160, Каролинский-162, три клона Регенераты (инв. № 65, 79 и 90), Робуста-195, два клона Робусты-236 (инв. № 80А и 156).

Bсе перечисленные клоны тополей можно рекомендовать как в массивные насаждения для выращивания балансовой древесины, так и для защитных насаждений и в озеленительные посадки. Исключение составляют только три клона тополя Регенераты, так как они женского пола и в начале лета сильно пушат, что неблагоприятно сказывается на экологической обстановке населенных пунктов.

Эффективность предлагаемого ассортимента несомненна. Более ранние результаты исследований, проведенных в других регионах страны - в южном направлении от Волгоградской зоны ЦентральноЧерноземных областей - (Астраханская область) и в северном (район ЦЧО) направлении, полученные на более старших участках, подтверждают преимущество энергии роста перечисленных клонов тополей над местным тополем-осокорем. Так, в условиях Астраханской области в 9-летнем возрасте тополя Робуста-236, Сакрау-59 и Брабантика-175 имели высоту 14,9 м; диаметр - 21-26 см [3]. В пойме Среднего Дона эти тополя в 14-летнем возрасте достигали в высоту 16-17,5 м и по диаметру - 16 см. На Украине в Донецкой степи в 13-летнем возрасте они имели высоту 20-24 м, диаметр - 23-28 см [6].

В ЦЧО в популетуме ЦНИИЛГиС средняя высота рекомендуемых выше клонов евро-американских тополей в 24-летнем возрасте была 28,6-31,4 м; диаметр - 36-45 см, расчетный запас древесины с учетом сохранности был равен $500-700 \mathrm{~m}^{3} /$ га; средний прирост составил 21-30 $\mathrm{m}^{3} /$ га в год [7]. Средний же запас местного тополя, осокоря, в автохтонных насаждениях и осинниках не превышает $200 \mathrm{~m}^{3} /$ га. 
Учитывая, что рост отобранных тополей в 5- и 7летнем возрасте в Волгоградской области превышал контроль по высоте в среднем на $39 \%$, по диаметру на $79 \%$, а также тенденцию сохранения этих различий с возрастом, можно прогнозировать, что к возрасту рубки запас древесины лучших сортов тополей в условиях Волгоградской области будет минимум на 40-80\% больше, чем местного широко культивируемого тополя. Фактически же, по данным, полученным на Нижней Волге [3] и в Центральной лесостепи [5, 7], эти различия составляют 150-200\%.

\section{ВЫВОДЫ}

Обобщая полученные результаты, можно отметить, что проведенные исследования позволили установить следующее:

- $\quad$ найдены оптимальные размеры площади питания укореняемых саженцев и густота посадки для различных групп тополей;

- изучены показатели приживаемости, роста и устойчивости тополей различных секций в условиях степной зоны;

- отобраны лучшие клоны тополей, отличающиеся адаптивным и соматическим гетерозиcom.

Лучшие формы и сорта тополей могут быть рекомендованы для внедрения их в Волгоградской области с целью повышения эффекта выращиваемых плантационных насаждений для получения балансовой древесины, а также создания лесов с необходимыми качествами защитных и рекреационных функций.

\section{СПИСОК ЛИТЕРАТУРЫ}

1. Иванников С. П., Царев А. П. Методика государственного испытания тополей / ВНИИЛМ. М., $1981.20 \mathrm{c}$.

2. Иозус А. П. Выделение перспективных видов тополей для защитного лесоразведения в Нижнем Поволжье // Интродукция, семеноводство и методы интенсивного размножения деревьев и кустарников, перспективных для защитного лесоразведения: Бюллетень ВНИАЛМИ. Волгоград, 1990. Вып. 2 (57). С. 19-21.

3. Казанцев И. Я. Интродукция и перспективы разведения тополей на Нижней Волге: Автореф. дис. ... канд. с.-х. наук. Воронеж, 1973. 31 с.

4. Методика государственного сортоиспытания лесных пород (Общая часть) / Государственная комиссия по сортоиспытанию сельскохозяйственных культур. М., 1981. 44 с.

5. Царев А. П. Сортоведение тополя. Воронеж: Изд-во ВГУ, 1985. 152 с.

6. Царева Р. П. Результаты испытания интродуцированных тополей в различных природных зонах ЕTC // Селекция быстрорастущих, орехоплодных и технических пород / НИИЛГиС. Воронеж, 1993. C. 42-49.

7. Царева Р. П. Рост и сохранность интродуцированных тополей в степной и лесостепной зонах // Генетико-селекционные основы улучшения лесов / НИИЛГиС. Воронеж, 1999. С. 184-196.

8. Царева Р. П., Царев В. А. Определение оптимальной густоты посадки стеблевых черенков при выращивании укорененного посадочного материала сортовых тополей // Лесное хозяйство. 1997. № 4. C. 37-39. 